\title{
Effect of exercise therapy on physical performance and functional balance in patients on maintenance renal hemodialysis: randomized controlled study
}

\author{
Ashraf Abdelaal Mohamed Abdelaal ${ }^{1, *}$, Ehab Mohamed Abdulaziz ${ }^{2}$ \\ 'Department of Physical Therapy for Cardiovascular/Respiratory Disorder and Geriatrics, Faculty of Physical Therapy, Cairo University, Cairo, Egypt \\ ${ }^{2}$ Consultant in Nephrology and Internal Medicine, National Institute of Liver, Gastroenterology \& Infectious Diseases, Cairo, Egypt
}

Physical performance (PP) and functional balance (FB) abnormalities are frequently encountered problems in patients on maintenance renal hemodialysis (MRH). Although the exercise therapy is an adjunctive to the routine medical care for patients with chronic kidney disease of various stages; but the benefits as well as the long-term effects of different exercises on the PP and FB in patients on MRH are not yet fully described. In this study; Sixty-six patients on MRH (36 males, $30 \mathrm{fe}-$ males), age 35-45 years, were randomly assigned into one of the three groups: aerobic exercise training group (AETG), resistance exercise training group (RETG), and control group (CG). The PP (evaluated using the 6-min walk test "6MWT") and the FB (evaluated via the Berg balance scale "BBS") were the main study outcomes evaluated prestudy (evaluation-1), after 3 months (evaluation-2) and 2 months poststudy cessation (evaluation-3). Results revealed that the PP and FB mean val- ues and percentages of changes at evaluation- 2 were $444.25 \pm 21.83$ $(33.1 \%), 413.57 \pm 28.55(22.52 \%), 337 \pm 12.23(0.33 \%) \mathrm{m}, 50.05 \pm 0.89$ $(22.95 \%), 49.95 \pm 2.06(22.52 \%), 41.28 \pm 1.75(0.94 \%)$ for AETG, RETG, and CG respectively. At evaluation-3; the PP and FB mean values and the percentage of changes were $425 \pm 21.49(27.36), 366.86 \pm 17.47(8.5 \%)$, $336.68(0.42 \%) \mathrm{m}, 44.4 \pm 1.85(8.06 \%), 42.95 \pm 2.04(5.003 \%), 39.48 \pm 2.06$ $(-4.44 \%)$ for AETG, RETG, and CG respectively. In conclusions; both aerobic exercise training (AET) and resistance exercise training (RET) have favorable effects, with the AET has higher short and long-term favorable effects on the PP and FB than RET in patients on MRH.

Keywords: Aerobic training, Resistance training, Physical performance, Functional balance, Renal hemodialysis

\section{INTRODUCTION}

Chronic kidney disease (CKD) is an alarming health problem affecting millions of people worldwide, (Patel et al., 2016) with a global prevalence of around $10 \%$ (Jha et al., 2013), this rate increased with age advance (Hasan et al., 2018). The CKD; with the urgency for maintenance renal hemodialysis $(\mathrm{MRH})$ is a globally debilitating problem. There's a continuous annual rise in the incidence of end-stage renal disease (Haddad and Adams, 2002), that is accompanied by increasing the number of patients on MRH (Chirakarnjanakorn et al., 2017).

Patients with CKD are generally suffering reduced activity lev- el (Hawkins et al., 2011), and muscle weakness that are all resulting in impaired physical function and loss of balance during everyday tasks (Clyne, 1996), which are major contributors for increased mortality in patients with CKD (Beddhu et al., 2015).

Easy fatigability, altered physical performance (PP) (Johansen, 2005), reduced exercise training frequency (Tentori et al., 2010), and increased tendency to be inactive (Beddhu et al., 2009) are prominent features in patients on $\mathrm{MRH}$, resulting in functional and physical impairments (Johansen, 2007) that are manifested mainly in deteriorated performance of the tasks of daily living activities (ADL) (Ifudu et al., 1994) and increased mortality rates in patients on $\mathrm{MRH}$; the concept that clarifies the importance of im-

\footnotetext{
*Corresponding author: Ashraf Abdelaal Mohamed Abdelaal

(iD) https://orcid.org/0000-0003-1319-7108

Department of Physical Therapy for Cardiovascular/Respiratory Disorder and Geriatrics, Faculty of Physical Therapy, Cairo University, 7 Ahmed Elzaiat St. Ben Elsaryat, EI Dokki- Giza, Cairo 12612, Egypt

E-mail: drashraf_pt79@yahoo.com

Received: April 2, 2019 / Accepted: May 28, 2019
}

This is an Open Access article distributed under the terms of the Creative Commons Attribution Non-Commercial License (http://creativecommons.org/licenses/by-nc/4.0/) which permits unrestricted non-commercial use, distribution, and reproduction in any medium, provided the original work is properly cited. 
plementing the exercise therapy as an essential component of the program of care for patients on MRH (Tentori et al., 2010).

Effective strategies are required to modify the cardiovascular risk factors that are commonly encountered in patients on MRH (Nishida et al., 2004). Patients' PP and functional balance (FB) are still the focus of interest of health care providers for patients on MRH (Wiberg and Zechner, 1997). Previous studies showed that exercise training has favorable effects on functional capacity and cardiovascular risk factors in those populations (Daul et al., 2004).

In spite of the continuously expanding body of knowledge regarding the benefits of exercise training in patients on $\mathrm{MRH}$; further investigations are required to fully clarify the effects of exercise training in those patients (Howden et al., 2012) through large samples and long duration studies (Afshar et al., 2010). Until recently; little is known about long-term effects of either aerobic or resistance exercise training on PP and FB. There is a continuous need to establish well-designed studies that provide detailed exercise prescription for patients on MRH. Furthermore; explanations are continuously warranted to describe the optimal benefits of aerobic and resistance exercise training in those populations, so the aim of this study as an extension to the previously published works in this field was to objectively evaluate the effects of aerobic and resistance exercise training on the $\mathrm{PP}$ and the $\mathrm{FB}$ in patients on MRH.

\section{MATERIALS AND METHODS}

\section{Subjects}

Eighty-Seven eligible volunteer patients on MRH were recruited to be enrolled in this study. Twenty-one patients were withdrawn and excluded before randomization and group allocation. The remaining 66 patients ( 36 males: 30 females) participated and completed this study (Fig. 1). The G-power program was used to determine the sample size in which the effect size $=0.42, \alpha=0.05$, power $(1-\beta$ error probability $)=0.82 \%$, with the number of groups $=3$, producing a total number of 63 participants to be enrolled in this study. Inclusion criteria: patient on MRH for more than 2 years

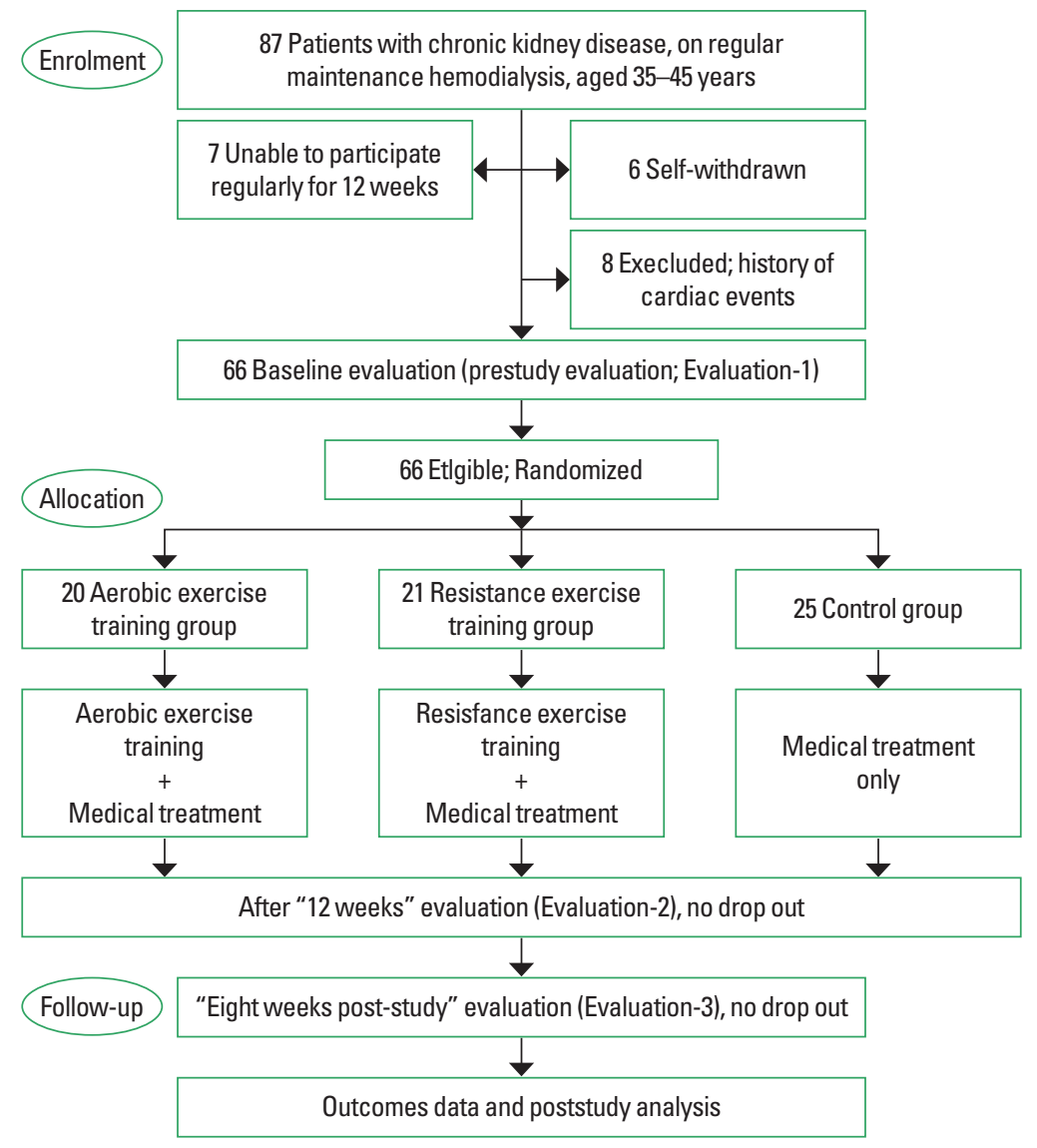

Fig. 1. Patient's flowchart. 
due to CKD, age 35-45 years old, and agreed to sign an informed consent for participation in the study. Exclusion criteria: participation in any previous exercise training program in the last 6 months, active infection within the last 4 weeks, body mass index (BMI) $\geq 35 \mathrm{~kg} / \mathrm{m}^{2}$, history of angina pectoris, lower limb amputation, chronic cardiovascular or pulmonary disorders interfering with patient safety and study results, history of the cerebrovascular or musculoskeletal insults that can affect the patient performance and accuracy of the study results.

\section{Study procedures}

All participants underwent the same battery of tests, were fully aware of the study goals and procedures, agreed to participate in this study and signed written informed consent at the beginning of this study that was carried out between May 2017 and November 2018, according to the principles of the Declaration of Helsinki 1975, revised Hong Kong 1989 and was approved by the institutional ethics committee of the Faculty of Physical Therapy, Cairo University (approval number No: P.T.REC/012/002123).

The nature of the study did not allow full blinding except for the evaluator and the data manager. After medical screening; 66 eligible patients were randomly allocated (using a computer program SAS Proc Plan; SAS Institute Cary NC, USA) into one of the three groups: the aerobic exercise training group (AETG; $n=$ 20), the resistance exercise training group (RETG; $n=21$ ), and the control group (CG; $n=25)$. All participants were encouraged to stabilize their medical treatment and the dialysis regimen throughout the study.

\section{Outcome measures}

The primary variables were the PP (evaluated using the 6-min walk test "6MWT") in meter, and the FB (evaluated using the Berg balance scale "BBS"). Each variable was evaluated at 3 timepoints throughout the study: prestudy (evaluation-1), after 3 months (evaluation-2) and 2 months poststudy cessation (evaluation-3). Demographic characteristics including weight, height and BMI were assessed using portable stadiometer (Detecto's ProMed 6129 medical scale, 203 E. Daugherty, Webb City, MO, USA). Resting heart rate (HR rest), systolic and diastolic blood pressure were evaluated from non-fistula arm using digital sphygmomanometer; (BTL CardioPoint ABPM apparatus "BTL Science and Technology [Shenzhen] Co., Ltd, China") following established guidelines (Williams et al., 2018).

Maximum heart rate (HRmax) was assessed through the modified symptom-limited Bruce exercise testing protocol using a stan- dard stress testing instrument, (Cardiac Science Quinton Q-Stress Test system, Cardiac Science International A/S, Kirke Vaerloesevej 14, DK-3500 Vaerloese, Dänemark) following established guidelines (Leehey et al., 2009). While the patient was closely monitored; the exercise testing started with 1.8 miles per hour speed, zero $\%$ inclination, both of which were gradually increased until exhaustion or the appearance of electrocardiogram abnormalities.

\section{PP evaluation}

After proper explanation of the test procedure; evaluation of PP was performed using the 6MWT. Following previously published guidelines (Kono et al., 2014); each participant walked in his/her own maximal pace through the 30 meter corridor for 6-minutes while putting-on the wireless fingertip pulse oximeter (IN-C013 China Rechargeable Handheld CMS 50I Contec Ear Fingertip Pulse Oximeter, ICEN Technology Company Limited, Amydimed, Guangdong China) to monitor the heart rate (HR), the covered distance was then recorded in meters at the end of the 6th minutes.

\section{FB evaluation: (evaluated via the "BBS")}

The FB was evaluated using the "BBS", consisted of 14 items, each item score ranges from zero (the lowest level of function) to four where (the highest level of performance). Activities performed in the BBS varied in difficulty from setting, to standing, to standing on one leg. The used materials included standard chairs (one with arm rests, one without), $15 \mathrm{ft}$ walkway, a stopwatch, a step and a ruler. Participant was asked to follow instructions in maintaining their balance while holding on certain position for specified time or achieving the requested task. The FB evaluations and data collection were done by the same examiner following standard guidelines (Berg et al., 1992).

\section{Interventions}

Each patient adhered to his/her prescribed training program; no serious abnormalities were recorded throughout the study.

\section{Aerobic exercise training program}

Each participant in this group $(n=20)$ received twelve weeks of gradually progressive aerobic exercise training (AET) three times/ week, on the nondialysis day's session schedule. Sufficient time (2-3 hours) was allowed after the breakfast before starting the session to avoid hypoglycemia.

After conducting a preliminary session to familiarize the patients on the treadmill and ensure safety measures during train- 
Table 1. The parameters of the aerobic and resistance exercise training programs

\begin{tabular}{lccl}
\hline Training & Weeks & Duration & \multicolumn{1}{c}{ Intensity } \\
\hline Aerobic training & $1-3$ & $30 \mathrm{~min}$ & $55 \%$ HRmax \\
& $4-6$ & $35 \mathrm{~min}$ & $60 \%$ HRmax \\
& $7-9$ & $40 \mathrm{~min}$ & $65 \%$ HRmax \\
& $10-12$ & $45 \mathrm{~min}$ & $70 \%$ HRmax \\
Resistance training & $1-2$ & & Two sets of 8 repetitions 70\% 1RM \\
& $3-4$ & Three sets of 8 repetitions 70\% 1RM \\
& $5-6$ & Two sets of 9 repetitions 70\% 1RM \\
& $7-8$ & Three sets of 9 repetitions 70\% 1RM \\
& $9-10$ & Two sets of 10 repetitions 70\% 1RM \\
& $11-12$ & Three sets of 10 repetitions 70\% 1RM \\
\hline
\end{tabular}

HRmax, maximum heart rate; 1RM, one-repetition maximum.

ing; each session started and ended with 5 to 10 min warm-up/ cool-down in the form of quite walking on the treadmill at intensity of 50\% HRmax. The exercise training intensity was closely monitored using the wireless pulse oximeter (IN-C013 China Rechargeable Handheld CMS 50I Contec Ear Fingertip Pulse Oximeter, ICEN Technology Company Limited, Amydi-med, Guangdong, China) worn by the patient and via the 15 points Borge's scale of perceived exertion.

The duration and intensity of the AET were gradually adjusted at regular intervals. The training duration started with $30 \mathrm{~min}$ and gradually increased to reach $45 \mathrm{~min}$ at the end of the study. The training intensity started with 55\% HRmax, reached 70\% HRmax at the end of the study (Table 1). Participants in the AETG were continuously directed to maintain their rate of perceived exertion between 11 and 13 on the Borge's scale.

\section{Resistance exercise training program}

The closely supervised resistance training was conducted 3 times weekly for 12 weeks. The program consisted of leg curl and leg extension exercises using Kettler 7752-800 multigym machine, EMS Physio (UK). Each session was preceded and followed by a warm-up/cool down phase typically as for the AETG.

The resistance training was conducted following previously published guidelines (Afshar et al, 2010; Watson et al., 2017). The training was started with two sets of eight repetitions $70 \%$ onerepetition maximum (1RM) and progress to reach three sets of ten repetitions $70 \% 1 \mathrm{RM}$ (Table 1). The training resistance was adjusted according to the newly achieved $1 \mathrm{RM}$. The process of $1 \mathrm{RM}$ re-evaluation and resistance adjustment was performed every 2 weeks. Participants in this group $(n=21)$ were directed to maintain their rate of perceived exertion between $15-17$ on the Borge's scale throughout the study.

\section{Control group}

Twenty-five participants were directed to maintain their regular medical care and their usual physical activity throughout the study but did not participate in any exercise training.

\section{Statistical analysis}

Data analysis was performed using IBM SPSS Statistics ver. 20.0 (IBM Co., Armonk, NY, USA) data are presented as mean and standard deviations. The Kolmogorov-Smirnov test was conducted to test data normal distribution. Changes in the PP and the FB mean values within and between groups at the three evaluation points were analyzed using the repeated measures analysis of variance with pairwise comparisons, with two "within-subjects" factors; treatment (AET, RET, control) and time (evaluation-1, evaluation-2, evaluation-3) to test hypothesis within and between groups. The level of significance was set at $P<0.05$.

\section{RESULTS}

Eighty-Seven patients were recruited to participate in this study, only 66 participants enrolled and completed the study and were randomly allocated to either the AETG $(n=20), \operatorname{RETG}(n=21)$, or $\mathrm{CG}(\mathrm{n}=25)$ (Fig. 1).

\section{Demographic characteristics}

Table 2 shows the patients' characteristics at the beginning of the study. There were nonsignificant differences between groups in the age (year), body weight $(\mathrm{kg})$, height $(\mathrm{m}), \mathrm{BMI}\left(\mathrm{kg} / \mathrm{m}^{2}\right)$, systolic blood pressure $(\mathrm{mmHg})$, diastolic blood pressure $(\mathrm{mmHg})$, Hours of dialysis per week, and average length of the hemodialysis vintage (months) $(P>0.05)$ (Table 2).

\section{Within group's comparison \\ At evaluation-2}

Results revealed that there were significant increases in mean values of PP by $33.1 \%, 22.52 \%$ and $\mathrm{FB}$ by $22.95 \%, 22.25 \%$ for the AETG and the RETG groups, respectively $(P<0.01)$, compared with nonsignificant decreases in the PP $(0.33 \% ; P=0.17)$ and the $\mathrm{FB}(0.09 \% ; P=0.76)$ mean values in the $\mathrm{CG}$ (Table 2).

\section{At evaluation-3}

Within the group's comparison between the evaluation-2 and -3 time points revealed that there were significant reduction in 
Table 2. The demographic characteristics of participants of all groups

\begin{tabular}{|c|c|c|c|c|c|}
\hline Variable & AETG $(n=20)$ & $\operatorname{REG}(n=21)$ & $C G(n=25)$ & T-value & $P$-value \\
\hline Age (yr) & $39.9 \pm 3.75$ & $39.67 \pm 4.07$ & $40.12 \pm 2.86$ & 0.09 & $0.91^{* *}$ \\
\hline Weight (kg) & $76.35 \pm 7.98$ & $75.81 \pm 9.47$ & $75.88 \pm 7.06$ & 0.03 & $0.97^{* *}$ \\
\hline Height (m) & $1.68 \pm 0.09$ & $1.67 \pm 0.1$ & $1.68 \pm 0.08$ & 0.16 & $0.85^{* *}$ \\
\hline $\mathrm{BMI}\left(\mathrm{kg} / \mathrm{m}^{2}\right)$ & $27.07 \pm 2.62$ & $27.32 \pm 2.68$ & $27.17 \pm 3.28$ & 0.40 & $0.96^{* *}$ \\
\hline $\mathrm{SBP}(\mathrm{mmHg})$ & $145.3 \pm 2.58$ & $144.76 \pm 2.79$ & $145.64 \pm 2.78$ & 0.60 & $0.55^{* *}$ \\
\hline $\mathrm{DBP}(\mathrm{mmHg})$ & $93.1 \pm 1.12$ & $92.95 \pm 1.57$ & $92.92 \pm 1.71$ & 0.90 & $0.92^{* *}$ \\
\hline Length of the hemodialysis vintage (mo) & $38.3 \pm 8.13$ & $37.86 \pm 8.77$ & $38.16 \pm 7.26$ & 0.02 & $0.98^{* *}$ \\
\hline Hours of dialysis/wk & $14.5 \pm 3.05$ & $14.67 \pm 2.61$ & $15.04 \pm 2.32$ & 0.25 & $0.78^{* *}$ \\
\hline HRmax (beat/min) & $151.55 \pm 3.28$ & $151.24 \pm 3.77$ & $150.6 \pm 3.42$ & 0.44 & $0.65^{* *}$ \\
\hline \multicolumn{6}{|l|}{ CKD etiology (\%) } \\
\hline Hypertension & 7 & 6 & 9 & & \\
\hline Glomerul-onephritis & 8 & 10 & 9 & & \\
\hline Unknown/others & 5 & 5 & 7 & & \\
\hline \multicolumn{6}{|l|}{ Smoking history } \\
\hline Smoker:ex-smoker:nonsmoker & $5: 9: 6$ & 7:8:6 & $7: 12: 6$ & & \\
\hline \multicolumn{6}{|l|}{ Gender } \\
\hline Female:male & 10:10 & $11: 10$ & $15: 10$ & & \\
\hline
\end{tabular}

AETG, aerobic exercise training group; REG, resistance exercise training group; CG, control group; BMI, body mass index; SBP, systolic blood pressure; DBP, diastolic blood pressure; HRmax, maximum heart rate; CDK, chronic kidney disease.

${ }^{*} P<0.05$, statistically significant difference.

Table 3. Physical performance and functional balance of all groups

\begin{tabular}{|c|c|c|c|c|c|c|c|c|c|}
\hline & \multicolumn{3}{|c|}{$\operatorname{AETG}(n=20)$} & \multicolumn{3}{|c|}{$\operatorname{RETG}(n=21)$} & \multicolumn{3}{|c|}{$C G(n=25)$} \\
\hline & Eval-1 & Eval-2 & Eval-3 & Eval-1 & Eval-2 & Eval-3 & Eval-1 & Eval-2 & Eval-3 \\
\hline \multicolumn{10}{|c|}{ Physical performance $(\mathrm{m})$} \\
\hline Mean \pm SD & $334.1 \pm 14.16$ & $444.25 \pm 21.83$ & $425 \pm 21.49$ & $338.38 \pm 14.12$ & $413.57 \pm 28.55$ & $366.86 \pm 17.47$ & $338.08 \pm 10.69$ & $337 \pm 12.23$ & $336.68 \pm 11.38$ \\
\hline$F(P$-value $)$ & \multicolumn{9}{|c|}{$256.78\left(<0.01^{*,+}\right)$} \\
\hline & \multicolumn{3}{|c|}{$502.1(<0.01 *)$} & \multicolumn{3}{|c|}{$94.05\left(<0.01^{*}\right)$} & \multicolumn{2}{|c|}{$1.97\left(0.17^{* *}\right)$} & \\
\hline & \multicolumn{3}{|c|}{$168.49\left(<0.01^{*}\right)$} & \multicolumn{3}{|c|}{$45.003\left(<0.01^{*}\right)$} & \multicolumn{3}{|c|}{$0.27\left(0.61^{* *}\right)$} \\
\hline & \multicolumn{3}{|c|}{$392.48\left(<0.01^{*}\right)$} & \multicolumn{3}{|c|}{$70.74\left(<0.01^{*}\right)$} & \multicolumn{3}{|c|}{$2.39\left(0.1^{* *}\right)$} \\
\hline \multicolumn{10}{|c|}{ Functional balance } \\
\hline Mean \pm SD & $41.15 \pm 2.35$ & $50.05 \pm 0.89$ & $44.4 \pm 1.85$ & $40.95 \pm 2.25$ & $49.95 \pm 2.06$ & $42.95 \pm 2.04$ & $41.36 \pm 2.22$ & $41.28 \pm 1.75$ & $39.48 \pm 2.06$ \\
\hline$F(P$-value $)$ & \multicolumn{9}{|c|}{$381.44\left(<0.05^{*,+}\right)$} \\
\hline & \multicolumn{3}{|c|}{$342.82\left(<0.01^{*}\right)$} & \multicolumn{3}{|c|}{$274.36\left(<0.05^{*}\right)$} & \multicolumn{2}{|c|}{$0.1\left(0.76^{* *}\right)$} & \\
\hline & \multicolumn{3}{|c|}{$222.38\left(<0.01^{*}\right)$} & \multicolumn{3}{|c|}{$381.11\left(<0.05^{*}\right)$} & \multicolumn{3}{|c|}{$40.5\left(0.06^{* *}\right)$} \\
\hline & \multicolumn{3}{|c|}{$231.11\left(<0.01^{*}\right)$} & \multicolumn{3}{|c|}{$240.51\left(<0.01^{*}\right)$} & \multicolumn{3}{|c|}{$23.87\left(0.07^{* *}\right)$} \\
\hline
\end{tabular}

AETG, aerobic exercise training group; RETG, resistance exercise training group; CG, control group; Eval, evaluation; SD, standard deviation.

${ }^{*} P<0.05$, statistically significant difference. ${ }^{+}$Degree of freedom $=2,62$.

the mean values of the PP by $4.33 \%, 10.93 \%$ and the FB by $11.29 \%, 13.98 \%$ for the AETG and the RETG groups, respectively $(P<0.01)$, compared with nonsignificant decrease in the PP $(P=0.61)$ and the FB $(P=0.06)$ mean values in the CG. Within the group's comparison between the evaluation- 1 and -3 time points revealed that there were significant increases in the mean values of the PP by $27.36 \%, 8.5 \%$ and the FB by $8.06 \%, 5 \%$ for the AETG and the RETG groups, respectively $(P<0.01)$, compared with nonsignificant reduction in the PP $(P=0.1)$ and the FB $(P=0.07)$ mean values in the CG (Table 3$)$.

\section{Between groups' comparison \\ At evaluation-1}

Results revealed that there were non-significant differences in 
Table 4. Between-groups comparison of physical performance and functional balance $(F, P$-values $)$

\begin{tabular}{lccc}
\hline & $\begin{array}{c}\text { Prestudy } \\
(\text { Eval-1) }\end{array}$ & $\begin{array}{c}\text { After 12 weeks } \\
\text { (Eval-2) }\end{array}$ & $\begin{array}{c}\text { Eight weeks } \\
\text { poststudy (Eval-3) }\end{array}$ \\
\hline Physical performance & $0.71,0.5^{* *}$ & $152.1,<0.01^{*}$ & $153.81,<0.01^{*}$ \\
Functional balance & $0.19,0.83^{* *}$ & $215.11,<0.01^{*}$ & $36.87,<0.01^{*}$ \\
\hline
\end{tabular}

Eval, evaluation.

${ }^{*} P<0.05$, statistically significant difference.

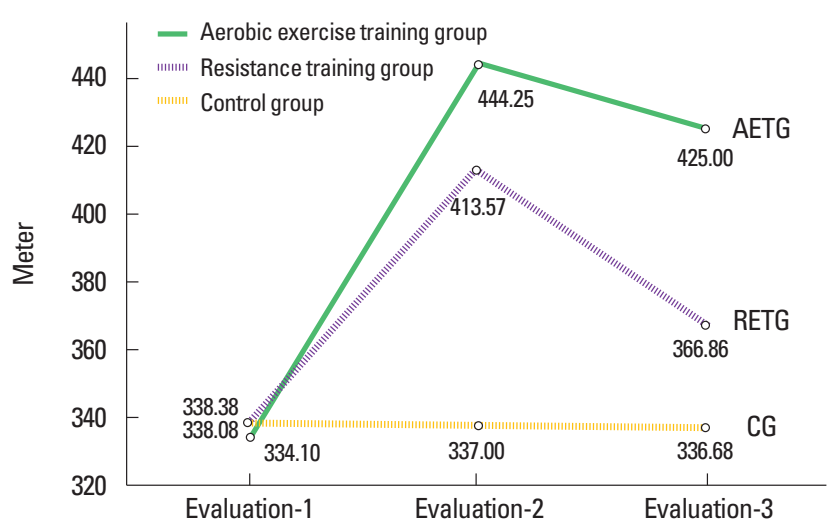

Fig. 2. Mean values of the physical performance in all groups. AETG, aerobic exercise training group; RETG, resistance exercise training group; CG, control group.

the $\mathrm{PP}(P=0.5)$ and the $\mathrm{FB}(P=0.83)$ mean values.

\section{At evaluation-2 and-3}

Results revealed that there were significant differences in the PP and the FB mean values, but in favor of the AETG group $(P<0.01)$ (Table 4; Figs. 2, 3)

\section{DISCUSSION}

The results of this study confirmed the importance of applying regular aerobic as well as strength training in patients on MRH. Aerobic as well as strength training proved to have favorable short and long-term effects on the PP and the FB in patients on MRH. The current study investigated short as well as long-term responses of the PP and the FB to exercise therapy in patients on MRH.

Factors led to the reduction of physical activity level in patients on regular MRH include decreased muscle strength (Johansen, 2005), increased co-morbidities (Sarnak and Levey, 2000), and deteriorated physiological status (Finkelstein et al., 2009). The importance of implementing the exercise training in the treatment of patient with CKD is not a recent concept (Goldberg et al., 1979). Previous studies reported physical as well as psychological benefits

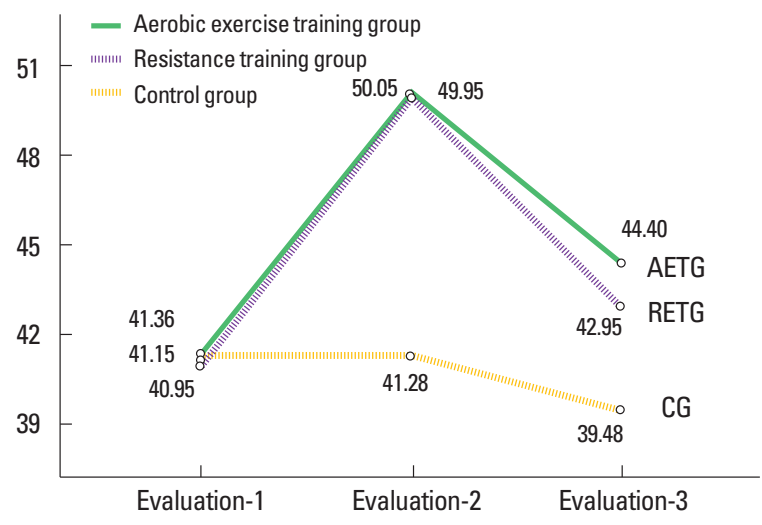

Fig. 3. Mean values of functional balance in all groups. AETG, aerobic exercise training group; RETG, resistance exercise training group; CG, control group.

of exercise training in patients on MRH (Goldberg et al., 1980; Goldberg et al., 1986; Hagberg et al.,1983). Pervious works reported that the benefits of regular exercise training included increased hemoglobin level, reduced hyperinsulinemia, and reduced the triglyceride level as well as limiting the depressive symptoms (Goldberg et al., 1980), all of which can positively impact the PP in patients on MRH.

Investigating the effects of resistance exercise training gained relatively lesser attention than that of AET in patients on $\mathrm{MRH}$, furthermore; the majority of these investigations evaluated the short-term effects of training and were done during the hemodialysis sessions. Despite its proven benefits; exercise training in patients on MRH is rarely conducted on a regular basis (Anding et al., 2015). Furthermore; data on short and long-term effects of exercise training in patients on MRH became mandatory to implement these training programs in the routine practical care of those patients (Capitanini et al., 2014; Williams et al., 2014).

The significant increases in the PP and the FB in patients on $\mathrm{MRH}$ in this study are comparable to results reported in previous studies. Patients on regular MRH are usually suffering reduced work capacity that can be efficiently improved by exercise practice (Clyne, 1996; Painter et al., 1986). Earlier study by Clyne et al. (1991), showed that exercise training for 3 months significantly increased the already deteriorated work capacity and muscle strength in patients with CKD. Muscular strength can be significantly improved after twenty weeks (Dobsak et al., 2012) or after 4 months of aerobic training in patients with CKD (Boyce et al., 1997). Both aerobic and resistance exercise training in the form of 2-sessions/ wk for 3 months can significantly increase the walking distance in patients with CKD (Rossi et al., 2014). Exercise training proved to reduce bodily pain and depression in addition to enhancing the 
self-esteem in patients on MRH (Molsted et al., 2004).

The significant increase in the PP in response to exercise training is mainly represented in shortening the time required to perform functional tasks in patients on MRH and can be attributed to increased muscular endurance (Bohm et al., 2014), increased $\mathrm{VO}_{2} \max$ (Aoike et al., 2015), and improved muscle power (Chen et al., 2010). Exercise training has cardiovascular benefits as well, exercise training improves the left ventricular mass index and hence; increasing cardiac output and ejection fraction in patients on MRH (Deligiannis et al., 1999). Regular exercise training can significantly improve the walking capacity and the tasks achievement time in patients on MRH (Manfredini et al., 2017), considering that AET with sufficiently higher intensity and longer study duration showed more favorable results on functional capacity than lower intensity and shorter duration training (Deligiannis et al., 1999; Konstantinidou et al., 2002; Painter et al., 2002).

Earlier studies reported that $\mathrm{CKD}$ is associated with progressive loss of strength in the large body muscles (Johansen et al., 2003; Storer et al., 2005). Regarding the PP and the FB responses to resistance exercise training in patients on $\mathrm{MRH}$; results of current study can be explained on the basis of the concept that strength training of 3- to 6-month increases the strength of large, proximal lower limbs muscles (Afshar et al., 2010; Chen et al., 2010; Song and Sohng, 2012), increase muscle size (Cheema et al., 2007) and produces concurrent improvements in knee extensor strength and performance of ADL (Chen et al., 2010). The underlying mechanisms of noticeable improvments on patients on $\mathrm{MRH}$ in response to exercise training are numerous, including the significant reduction in the number of atrophic lower limb muscles fibers and accompanied increase in its cross-sectional area especially in type II muscle fibers (Kouidi et al., 1998), significant reduction in inflammatory markers and improvement in body composition (Moraes et al., 2014). The post-training physical improvments in patients on MRH can be partly explained by the training-related increase in the protein synthesis (Booth et al., 1998; Rennie et al., 2004), increasing blood flow to the exercised muscles (Mohseni et al., 2013) and the favorable adaptations within the skeletal muscles in response to the provided training in patient on $\mathrm{MRH}$ (Kouidi et al., 1998; Violan et al., 2002). The exercise training counteracts the state of muscle atrophy presented in patients on $\mathrm{MRH}$ and so reducing the incidence of muscular fatigue and produces significant improvments in ADL acheivments (van Vilsteren et al., 2005). Adding to that; the effects of regular exercise etraining are not limited to physical aspects but extends to include psychological aspects as well. Regular exercise training even for a short time proved to significantly improve the emotional status and health related quality of life (Tomich et al., 2014) and hence positively impacting the regular participation and the PP of various activities in patients on MRH.

Some limitations were encountered in the current study. Efforts were done to avoid bias and to optimize blinding, but the nature of the study limits the double blinding process since both patients and physiotherapist should know the group allocation and the type of the exercise training. Absence of combined aerobic plus strength exercise training group, relatively short follow-up duration are additional limitations. Future studies should try to overcome these limitations. In conclusion; both AET and RET have extended favorable effects on the PP and FB in patients on MRH. The AET showed higher short and long-term favorable effects than the RET on the PP and FB in patients on MRH. So the AET is still the recommended approach to improve the $\mathrm{PP}$ and $\mathrm{FB}$ in patients on MRH.

\section{CONFLICT OF INTEREST}

No potential conflict of interest relevant to this article was reported.

\section{REFERENCES}

Afshar R, Shegarfy L, Shavandi N, Sanavi S. Effects of aerobic exercise and resistance training on lipid profiles and inflammation status in patients on maintenance hemodialysis. Indian J Nephrol 2010;20:185189.

Anding K, Bär T, Trojniak-Hennig J, Kuchinke S, Krause R, Rost JM, Halle M. A structured exercise programme during haemodialysis for patients with chronic kidney disease: clinical benefit and long-term adherence. BMJ Open 2015;5:e008709.

Aoike DT, Baria F, Kamimura MA, Ammirati A, de Mello MT, Cuppari L. Impact of home-based aerobic exercise on the physical capacity of overweight patients with chronic kidney disease. Int Urol Nephrol 2015;47:359-367.

Beddhu S, Baird BC, Zitterkoph J, Neilson J, Greene T. Physical activity and mortality in chronic kidney disease (NHANES III). Clin J Am Soc Nephrol 2009;4:1901-1906.

Beddhu S, Wei G, Marcus RL, Chonchol M, Greene T. Light-intensity physical activities and mortality in the United States general population and CKD subpopulation. Clin J Am Soc Nephrol 2015;10:11451153.

Berg KO, Wood-Dauphinee SL, Williams JI, Maki B. Measuring balance 
in the elderly: validation of an instrument. Can J Public Health 1992;83 Suppl 2:S7-11.

Bohm C, Stewart K, Onyskie-Marcus J, Esliger D, Kriellaars D, Rigatto C. Effects of intradialytic cycling compared with pedometry on physical function in chronic outpatient hemodialysis: a prospective randomized trial. Nephrol Dial Transplant 2014;29:1947-1955.

Booth FW, Tseng BS, Flück M, Carson JA. Molecular and cellular adaptation of muscle in response to physical training. Acta Physiol Scand 1998;162:343-350

Boyce ML, Robergs RA, Avasthi PS, Roldan C, Foster A, Montner P, Stark D, Nelson C. Exercise training by individuals with predialysis renal failure: cardiorespiratory endurance, hypertension, and renal function. Am J Kidney Dis 1997;30:180-192.

Capitanini A, Lange S, D'Alessandro C, Salotti E, Tavolaro A, Baronti ME, Giannese D, Cupisti A. Dialysis exercise team: the way to sustain exercise programs in hemodialysis patients. Kidney Blood Press Res 2014;39:129-133.

Cheema B, Abas H, Smith B, O'Sullivan A, Chan M, Patwardhan A, Kelly J, Gillin A, Pang G, Lloyd B, Singh MF. Progressive exercise for anabolism in kidney disease (PEAK): a randomized, controlled trial of resistance training during hemodialysis. J Am Soc Nephrol 2007;18:15941601.

Chen JL, Godfrey S, Ng TT, Moorthi R, Liangos O, Ruthazer R, Jaber BL, Levey AS, Castaneda-Sceppa C. Effect of intra-dialytic, low-intensity strength training on functional capacity in adult haemodialysis patients: a randomized pilot trial. Nephrol Dial Transplant 2010;25:19361943.

Chirakarnjanakorn S, Navaneethan SD, Francis GS, Tang WH. Cardiovascular impact in patients undergoing maintenance hemodialysis: clinical management considerations. Int J Cardiol 2017;232:12-23.

Clyne N. Physical working capacity in uremic patients. Scand J Urol Nephrol 1996;30:247-252.

Clyne N, Ekholm J, Jogestrand T, Lins LE, Pehrsson SK. Effects of exercise training in predialytic uremic patients. Nephron 1991;59:84-89.

Daul AE, Schäfers RF, Daul K, Philipp T. Exercise during hemodialysis. Clin Nephrol 2004;61 Suppl 1:S26-30.

Deligiannis A, Kouidi E, Tassoulas E, Gigis P, Tourkantonis A, Coats A. Cardiac effects of exercise rehabilitation in hemodialysis patients. Int $\mathrm{J}$ Cardiol 1999;70:253-266.

Dobsak P, Homolka P, Svojanovsky J, Reichertova A, Soucek M, Novakova M, Dusek L, Vasku J, Eicher JC, Siegelova J. Intra-dialytic electrostimulation of leg extensors may improve exercise tolerance and quality of life in hemodialyzed patients. Artif Organs 2012;36:71-78.

Finkelstein FO, Wuerth D, Finkelstein SH. Health related quality of life and the CKD patient: challenges for the nephrology community. Kid- ney Int 2009;76:946-952.

Goldberg AP, Geltman EM, Gavin JR 3rd, Carney RM, Hagberg JM, Delmez JA, Naumovich A, Oldfield MH, Harter HR. Exercise training reduces coronary risk and effectively rehabilitates hemodialysis patients. Nephron 1986;42:311-316.

Goldberg AP, Hagberg J, Delmez JA, Carney RM, McKevitt PM, Ehsani AA, Harter HR. The metabolic and psychological effects of exercise training in hemodialysis patients. Am J Clin Nutr 1980;33:1620-1628.

Goldberg AP, Hagberg JM, Delmez JA, Florman RW, Harter HR. Effects of exercise training on coronary risk factors in hemodialysis patients. Proc Clin Dial Transplant Forum 1979;9:39-43.

Haddad F, Adams GR. Selected contribution: acute cellular and molecular responses to resistance exercise. J Appl Physiol (1985) 2002;93:394403.

Hagberg JM, Goldberg AP, Ehsani AA, Heath GW, Delmez JA, Harter HR. Exercise training improves hypertension in hemodialysis patients. Am J Nephrol 1983;3:209-212.

Hasan M, Sutradhar I, Gupta RD, Sarker M. Prevalence of chronic kidney disease in South Asia: a systematic review. BMC Nephrol 2018;19:291.

Hawkins MS, Sevick MA, Richardson CR, Fried LF, Arena VC, Kriska AM. Association between physical activity and kidney function: National Health and Nutrition Examination Survey. Med Sci Sports Exerc 2011;43:1457-1464.

Howden EJ, Fassett RG, Isbel NM, Coombes JS. Exercise training in chronic kidney disease patients. Sports Med 2012;42:473-488.

Ifudu O, Paul H, Mayers JD, Cohen LS, Brezsnyak WF, Herman AI, Avram MM, Friedman EA. Pervasive failed rehabilitation in center-based maintenance hemodialysis patients. Am J Kidney Dis 1994; 23:394-400.

Jha V, Garcia-Garcia G, Iseki K, Li Z, Naicker S, Plattner B, Saran R, Wang AY, Yang CW. Chronic kidney disease: global dimension and perspectives. Lancet 2013;382:260-272.

Johansen KL. Exercise and chronic kidney disease: current recommendations. Sports Med 2005;35:485-499.

Johansen KL. Exercise in the end-stage renal disease population. J Am Soc Nephrol 2007;18:1845-1854.

Johansen KL, Shubert T, Doyle J, Soher B, Sakkas GK, Kent-Braun JA. Muscle atrophy in patients receiving hemodialysis: effects on muscle strength, muscle quality, and physical function. Kidney Int 2003;63: 291-297.

Kono K, Nishida Y, Moriyama Y, Yabe H, Taoka M, Sato T. Investigation of factors affecting the six-minute walk test results in hemodialysis patients. Ther Apher Dial 2014;18:623-627.

Konstantinidou E, Koukouvou G, Kouidi E, Deligiannis A, Tourkantonis A. Exercise training in patients with end-stage renal disease on hemo- 
dialysis: comparison of three rehabilitation programs. J Rehabil Med 2002;34:40-45.

Kouidi E, Albani M, Natsis K, Megalopoulos A, Gigis P, Guiba-Tziampiri $\mathrm{O}$, Tourkantonis A, Deligiannis A. The effects of exercise training on muscle atrophy in haemodialysis patients. Nephrol Dial Transplant 1998;13:685-699.

Leehey DJ, Moinuddin I, Bast JP, Qureshi S, Jelinek CS, Cooper C, Edwards LC, Smith BM, Collins EG. Aerobic exercise in obese diabetic patients with chronic kidney disease: a randomized and controlled pilot study. Cardiovasc Diabetol 2009;8:62.

Manfredini F, Mallamaci F, D’Arrigo G, Baggetta R, Bolignano D, Torino C, Lamberti N, Bertoli S, Ciurlino D, Rocca-Rey L, Barillà A, Battaglia Y, Rapanà RM, Zuccalà A, Bonanno G, Fatuzzo P, Rapisarda F, Rastelli S, Fabrizi F, Messa P, De Paola L, Lombardi L, Cupisti A, Fuiano G, Lucisano G, Summaria C, Felisatti M, Pozzato E, Malagoni AM, Castellino P, Aucella F, Abd ElHafeez S, Provenzano PF, Tripepi G, Catizone L, Zoccali C. Exercise in patients on dialysis: a multicenter, randomized clinical trial. J Am Soc Nephrol 2017;28:1259-1268.

Mohseni R, Emami Zeydi A, Ilali E, Adib-Hajbaghery M, Makhlough A. The effect of intradialytic aerobic exercise on dialysis efficacy in hemodialysis patients: a randomized controlled trial. Oman Med J 2013;28: 345-349.

Molsted S, Eidemak I, Sorensen HT, Kristensen JH. Five months of physical exercise in hemodialysis patients: effects on aerobic capacity, physical function and self-rated health. Nephron Clin Pract 2004;96:c76-81.

Moraes C, Marinho SM, da Nobrega AC, de Oliveira Bessa B, Jacobson LV, Stockler-Pinto MB, da Silva WS, Mafra D. Resistance exercise: a strategy to attenuate inflammation and protein-energy wasting in hemodialysis patients? Int Urol Nephrol 2014;46:1655-1662.

Nishida C, Uauy R, Kumanyika S, Shetty P. The joint WHO/FAO expert consultation on diet, nutrition and the prevention of chronic diseases: process, product and policy implications. Public Health Nutr 2004; 7(1A):245-250.

Painter P, Messer-Rehak D, Hanson P, Zimmerman SW, Glass NR. Exercise capacity in hemodialysis, CAPD, and renal transplant patients. Nephron 1986;42:47-51.

Painter P, Moore G, Carlson L, Paul S, Myll J, Phillips W, Haskell W. Effects of exercise training plus normalization of hematocrit on exercise capacity and health-related quality of life. Am J Kidney Dis 2002;39: 257-265.

Patel N, Golzy M, Nainani N, Nader ND, Carter RL, Lohr JW, Arora P. Prevalence of various comorbidities among veterans with chronic kidney disease and its comparison with other datasets. Ren Fail 2016;38: 204-208.

Rennie MJ, Wackerhage H, Spangenburg EE, Booth FW. Control of the size of the human muscle mass. Annu Rev Physiol 2004;66:799-828.

Rossi AP, Burris DD, Lucas FL, Crocker GA, Wasserman JC. Effects of a renal rehabilitation exercise program in patients with CKD: a randomized, controlled trial. Clin J Am Soc Nephrol 2014;9:2052-2058.

Sarnak MJ, Levey AS. Cardiovascular disease and chronic renal disease: a new paradigm. Am J Kidney Dis 2000;35(4 Suppl 1):S117-131.

Song WJ, Sohng KY. Effects of progressive resistance training on body composition, physical fitness and quality of life of patients on hemodialysis. J Korean Acad Nurs 2012;42:947-956.

Storer TW, Casaburi R, Sawelson S, Kopple JD. Endurance exercise training during haemodialysis improves strength, power, fatigability and physical performance in maintenance haemodialysis patients. Nephrol Dial Transplant 2005;20:1429-1437.

Tentori F, Elder SJ, Thumma J, Pisoni RL, Bommer J, Fissell RB, Fukuhara S, Jadoul M, Keen ML, Saran R, Ramirez SP, Robinson BM. Physical exercise among participants in the Dialysis Outcomes and Practice Patterns Study (DOPPS): correlates and associated outcomes. Nephrol Dial Transplant 2010;25:3050-3062.

Tomich GM, Bernardino LS, Ferreira FO. Impact of physical therapy on functional capacity and life quality of patients with chronic kidney disease. Fisioter Mov 2014;27:643-651.

van Vilsteren MC, de Greef MH, Huisman RM. The effects of a low-tomoderate intensity pre-conditioning exercise programme linked with exercise counselling for sedentary haemodialysis patients in The Netherlands: results of a randomized clinical trial. Nephrol Dial Transplant 2005;20:141-146.

Violan MA, Pomes T, Maldonado S, Roura G, De la Fuente I, Verdaguer T, Lloret R, Torregrosa JV, Campistol JM. Exercise capacity in hemodialysis and renal transplant patients. Transplant Proc 2002;34:417-418.

Watson EL, Viana JL, Wimbury D, Martin N, Greening NJ, Barratt J, Smith AC. The effect of resistance exercise on inflammatory and myogenic markers in patients with chronic kidney disease. Front Physiol 2017;8:541.

Wiberg E, Zechner E. Assessment of functional capacity in patients with kidney failure - reliability test of a battery of tests. Nordisk Fysioterapi 1997;1:127-134.

Williams AD, Fassett RG, Coombes JS. Exercise in CKD: why is it important and how should it be delivered? Am J Kidney Dis 2014;64:329-331.

Williams B, Mancia G, Spiering W, Agabiti Rosei E, Azizi M, Burnier M, Clement DL, Coca A, de Simone G, Dominiczak A, Kahan T, Mahfoud F, Redon J, Ruilope L, Zanchetti A, Kerins M, Kjeldsen SE, Kreutz R, Laurent S, Lip GYH, McManus R, Narkiewicz K, Ruschitzka F, Schmieder RE, Shlyakhto E, Tsioufis C, Aboyans V, Desormais I; ESC Scientific Document Group. 2018 ESC/ESH Guidelines for the management of arterial hypertension. Eur Heart J 2018;39:3021-3104. 